ANATOMICAL VARIATIONS OF THE CYSTIC DUCT AND THEIR SURGICAL IMPLICATIONS IN SUDANESE POPULATION: A CADAVERIC STUDY

Ali Yasen Yasen MohamedAhmed ${ }^{* 1}$, Alaa A. Salih ${ }^{2}$, Mohamed Alsadiq Abdallah Adam 2, Salma Saeed Sulaiman Mohammed 1, Mohamed Elghazali Ahmed Basheer Elhasan ${ }^{1}$, Mohamed Ahmed Abdalla ${ }^{3}$.

${ }^{1}$ Sudan Medical Specialization Board, Sudan.

${ }^{2} 6^{\text {th }}$ Year Medical Student, University of Khartoum Faculty of Medicine, Sudan.

${ }^{3}$ Department of Anatomy, University of Khartoum Faculty of Medicine, Sudan.

\title{
ABSTRACT
}

Background: Anatomic variations of cystic ducts are common and continuously encountered during Surgical and radiological interventions. Failure to identify these clinically important variations may result in complications during surgical or endoscopic procedures.

Patients and methods: This is an observational descriptive cross-sectional study. 65 cadavers in the dissecting rooms of the medical colleges, in which the length and mode of insertion of cystic duct (CD) into common bile duct (CBD) were observed.

Results: The mean length of the CD in the cadavers examined was $(2.06 \pm 1.03)$ with a minimum length of $d^{\prime \prime} 0.5 \mathrm{~cm}$ and a maximum of $5 \mathrm{~cm}$. Regarding the mode of insertion of $C D$ into the CBD; $53.8 \%$ were found to have a low junction between the $\mathrm{CD}$ and common hepatic duct (CHD) which is considered the normal insertion. $46.2 \%$ found to be abnormal variations of insertion; short CD $\left(d^{\prime \prime} 0.5 \mathrm{~cm}\right)$ observed in $10.8 \%$; whereas in $13.8 \%$ of cadavers we found that the $\mathrm{CD}$ is adherent to the $\mathrm{CHD}$ and runs in parallel to it. In $7.8 \%$ there was a high junction between the $C D$ and $C B D$ and in $9.2 \%$ we found that $C D$ courses anterior or posterior to CBD and joins it medially.

Conclusion: $C D$ variations are not uncommon and it is important to identify these anatomical variations. $A$ detailed knowledge of the extra hepatic biliary tract, as well as of its variations, is important for the diagnostic and therapeutic success in many clinical situations since they allow the surgeon prompt identification of certain pathologies, making surgical procedures more accurate and affective.

KEY WORDS: Cystic Duct, Common Bile Duct, Common Hepatic Duct, Anatomical Variations.

Address for Correspondence: Dr. Ali Yasen Yasen MohamedAhmed,MBBS,MSc,MD,MRCS. P.O. Box 102, Alqasr Avenue, Khartoum 11111, Sudan. E-Mail: dr.aliyasen1@gmail.com

Access this Article online

Quick Response code

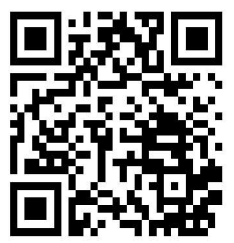

DOI: 10.16965/ijar.2019.131

Journal Information

\section{International Journal of Anatomy and Research}

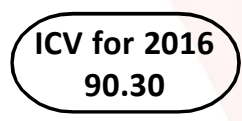

ISSN (E) 2321-4287 | ISSN (P) 2321-8967

https://www.ijmhr.org/ijar.htm

DOI-Prefix: https://dx.doi.org/10.16965/ijar

(cc) $\mathrm{Br}-\mathrm{Mc}-\mathrm{BH}$

Article Information

Received: 31 Jan 2019

Peer Review: 02 Feb 2019

Revised: None
Accepted: 07 Mar 2019

Published (O): 05 Apr 2019

Published (P): 05 Apr 2019

\section{INTRODUCTION}

Anatomic variations of cystic duct (CD) are not uncommon and are continuously encountered during imaging and surgery. Failure to identify the clinically significant variations may result in complications during surgical, endoscopic, or percutaneous intervention procedures. The purpose of this study is to identify the characteristics of various anatomical variants of cystic duct in Sudanese cadavers and to demonstrate the prevalence of cystic duct variations among Sudanese population.

The cystic duct joins the gallbladder to the extrahepatic biliary tree; its point of attachment 
into the extrahepatic bile duct marks the division between the common hepatic duct (CHD) and the common bile duct (CBD). The CD length usually measures $(2-4) \mathrm{cm}$ and contains prominent concentric folds known as the spiral valves of Heister. The CD frequently follows a tortuous or spiral course. Its normal diameter is variable, ranging from 1 to $5 \mathrm{~mm}$. The CD is usually attached to the extrahepatic bile duct approximately midway between the porta hepatis of liver and the ampulla of Vater in the duodenum. However, the point at which the CD joins the extrahepatic bile duct is variable, ranging from high at the level of the porta hepatis to low at the level of the ampulla [1-4]. Most commonly, the $C D$ inserts from a right lateral position but may have an anterior or posterior spiral insertion, low lateral attachment with a common sheath enclosing the $C D$ and $C B D$, proximal attachment, or low medial attachment at or close to the ampulla of Vater [3,5-7].

\section{PATIENTS AND METHODS}

This is an observational descriptive cross-sectional study Conducted in Dissecting rooms of the faculties of medicine in Khartoum state during the period from September 2017 till April 2018. All Well-dissected cadavers with no disruption of the concerned area in medical colleges at Khartoum state were included in the Study. Data was collected using a master sheet, Data analysis was done using the Statistical Package for Social Sciences (SPSS) version 22 software and result obtained expressed in tables and simple figures.

\section{RESULTS}

A total of 65 cadavers were examined for the length of the cystic duct and the mode of insertion of the cystic duct into common hepatic duct. $83.6 \%$ were males and $16.4 \%$ were females. The mean length of the $C D$ in the cadavers examined was $(2.06 \pm 1.03) \mathrm{cm}$ with a minimum length of $0.5 \mathrm{~cm}$ and a maximum of 5 $\mathrm{cm}$. Regarding the mode of insertion of $C D$ into CBD; $52 \%$ were found to have a low junction between the cystic duct and common hepatic duct which is considered the normal insertion.

Forty-eight percent were found to have abnormal variations of insertion; short $C D(\leq 0.5 \mathrm{~cm})$ was observed in $10.8 \%$; whereas in $13.8 \%$ we found that the cystic duct is adherent to the common hepatic duct and runs in parallel to it. In $7.8 \%$ there was a high junction between the $C D$ and $C B D$ and in $9.2 \%$ we found that the $C D$ courses anterior or posterior to $\mathrm{CBD}$ and joins it medially (table 1).

No significant association between the gender and length of the $C D$ or gender and the mode of insertion were found with $P$ values of $(P=.385)$ $(P=.212)$ respectively.

Table 1: Show the distribution of mode of insertion of CD into $\mathrm{CBD}$ in cadavers.

\begin{tabular}{|l|c|c|}
\hline \multicolumn{1}{|c|}{ Variation } & $\begin{array}{c}\text { Number Of } \\
\text { Cadavers }\end{array}$ & percent \\
\hline Low junction between CD and CHD & 35 & $53.80 \%$ \\
\hline CD adherent to the CHD run parallel together & 9 & $13.80 \%$ \\
\hline Absence of CD or very short CD ( $\leq 0.5 \mathrm{~cm})$ & 7 & $10.80 \%$ \\
\hline $\begin{array}{l}\text { CD crosses anterior or posterior to CHD and joins it } \\
\text { medially }\end{array}$ & 6 & $9.20 \%$ \\
\hline High junction between the CD and the CHD & 5 & $7.80 \%$ \\
\hline CD drains into right hepatic duct & 3 & $4.60 \%$ \\
\hline
\end{tabular}

\section{DISCUSSION}

Bile duct injury is a serious complication during cholecystectomy. One of the major causes of bile duct injury is failure to recognize the biliary anatomy, specifically in the presence of anatomical variants. Complete transection or ligation of common bile duct occurs when CBD is mistaken for cystic duct and it is one of the serious complications of laparoscopic and open cholecystectomy [8]. Pervious knowledge of the CD anatomy and its possible variations helps in proper interpretation of disease process and avoids iatrogenic injuries during surgery $[8,9]$.

Variations in the anatomy of extrahepatic biliary ducts have long been recognized and a wide range variability is noticed in the pattern of $C D$ and its junction with extrahepatic bile duct. Classical anatomy of the $C D$ joining the $\mathrm{CHD}$ at its middle third from the lateral aspect is seen in $58 \%-75 \%$ of cases in the literature $[10,11]$ compared to this study which found only in $52 \%$ of the cases. The length of the cystic duct in previous studies ranged from 7 to $39 \mathrm{~mm}$ (mean $19 \pm 7 \mathrm{~mm}$ ) $[12,13]$ In this study the length of the cystic duct fell within the range of 0.5- 5 $\mathrm{cm}$ (mean was $2.06 \pm 1.03$ ). According to CaroliBosc et al., there is a link between the length of the $C D$ and it's left lateral attachment to the 
gallbladder, so that most laterally attached ducts had more than $3 \mathrm{~cm}$ in length, whereas the left attachment of the $C D$ would be associated with an increased incidence of biliary stones [14].

A long parallel CHD and CD were reported in $1.2-25 \%$ of the population, where the two ducts are enclosed by one fibrous sheath and show a parallel course for at least $2 \mathrm{~cm}[3,15-18]$.

This variation was noted in $13.8 \%$ of cases in this study. If this variant is not recognized, the extrahepatic bile duct can be mistaken for the $C D$ and that can result in inadvertent transection or ligation of the extrahepatic bile duct and result in a postoperative complication. If the long parallel CD is clipped or transected too close to the CHD, the CHD may undergo strictures or narrowing at this site. In patients with long parallel $C D$ and cases with medial insertion, usually a long cystic duct stump is left after cholecystectomy, which might get inflamed or get dilated with mucous and calculus disease leading to postcholecystectomy syndrome [19- 21].

Medial insertion of the $C D$ into $C B D$ with posterior or anterior spiral course was observed in $9.2 \%$ of cases. Medial insertion of the CD was reported in $10-18 \%$ of cases in previous studies $[3,15,22,23]$. This variant is due to embryological malrotation of the which is due to faulty transfer of the choledochoduodenal junction during rotation of the duodenum. The twist of the duct during its formation may be either clockwise or counterclockwise causing the cystic duct to take a spiral course either anterior or posterior to the common hepatic duct [3].

Surgical Dissection of the medial CD up to its end is considered hazardous and it is advised to leave a long stump of cystic duct [16].

The presence of short or absent cystic duct is a rare but important variant and increases the chance of biliary injury, especially during laparoscopic cholecystectomy [24] and the congenital absence of $C D$ necessitates open cholecystectomy [25].

Most cases of apparently absent or short cystic duct are due to severe fibrosis and impaction of stone at the junction of the duct and a contracted chronically inflamed gallbladder. The true congenital type of absent cystic duct is very rare and results from failure of development of the proximal part of the caudal division of the hepatic diverticulum [26-29]. Short cystic duct which is defined as CD having a length of equal to or less than $5 \mathrm{~mm}$ was reported in $1.3 \%-2.6 \%$ of cases in previous studies $[10,15,30,25]$. This anomaly was reported in $7(10.8 \%)$ of cases in this study which is much higher than previous Studies. During surgery when surgeons try to visualize the cystic duct by giving upward traction on gall bladder, the presence of short cystic may lead to tenting of the CHD or CBD and cause it to simulate the appearance of the CD. In such a situation, the common bile duct may be inadvertently ligated or transected [30]. There were five cases $(7.8 \%)$ in which a high junction between the cystic duct and the common hepatic duct was observed and four cases (4.6\%) with cystic ducts draining into the RHD. It is crucial to diagnose the high union of the $C D$ into the CHD, aberrant cystic duct drainage into the right hepatic duct, and aberrant junction of intrahepatic bile ducts to the cystic duct as these variants can be missed during surgery, resulting in inadvertent transaction and ligation of the right hepatic duct [ 31,32]. No double cystic cases was seen in this study. Cystic duct duplication in the presence of single gall bladder is a very rare anomaly and is associated with higher risk of complication during laparoscopic cholecystectomy and postoperative bile leakage $[12,33]$.

\section{ABBREVIATIONS}

CD - Cystic duct.

CBD - Common Bile Duct.

CHD - Common Hepatic Duct.

RHD - Right Hepatic duct.

\section{Conflicts of Interests: None}

\section{REFERENCES}

[1]. Netter FH. The Ciba collection of medical illustrations. Vol 111. Digestive system. Part III. Liver, biliary tract and pancreas. Summit, NJ: Ciba Pharmaceutical, 1957; 22-24.

[2]. Friedman AC, Sachs L. Embryology, anatomy, histology and radiologic anatomy. In: Friedman AC, ed. Radiology of the liver, biliary tract, pancreas and spleen. Baltimore, Md: Williams \& Wilkins, 1987; 305-332.

[3]. M. J. Shaw, P. J.Dorsher, and J. A.Vennes, "Cystic duct anatomy: an endoscopic perspective," American Journal of Gastroenterology, 1993;88(12):21022106. 
[4]. Zeman RK, Burrell MI. Gallbladder and bile duct imaging. New York, NY: Churchill-Livingstone, 1987; 36-46.

[5]. Puente SG, Bannura GC. Radiological anatomy of the biliary tract: variations and congenital abnormalities. World J Surg 1983; 7:271-276.

[6]. Hayes MA, Goldenberg IS, Bishop CC. The developmental basis for bile duct anomalies. Surg Gynecol Obstet 1958;107:447-456.

[7]. Schulte SJ. Embryology and congenital anomalies of the biliary and pancreatic ducts. In: Silvis SE, Rohrmann CA, Ansel HJ, eds. Techniques and interpretation of endoscopic retrograde cholangi o-pancreatography with endoscopic intervention. New York, NY: Igaku-Shoin, 1995;114-145.

[8]. K. T. Buddingh, A. N. Morks, H. O. Ten Cate Hoede maker et al., "Documenting correct assessment of biliary anatomy during laparoscopic cholecystectomy," Surgical Endoscopy 2012;26(1):79-85.

[9]. A. Hatzidakis, P. Venetucci, M. Krokidis, and V. Iaccarino, "Percutaneous biliary interventions through the gallbladder and the cystic duct: what radiologists need to know," Clinical Radiology, 2014;69(12):1304-1311.

[10]. K.A.H.Talpur, A. A. Laghari, S. A. Yousfani,A.M.Malik,A. I. Memon, and S. A. Khan, "Anatomical variations and congenital anomalies of extra hepatic biliary system encountered during laparoscopic cholecystectomy," Journal of the Pakistan Medical Association, 2010;60(2):89-93.

[11]. Choi JW, Kim TK, Kim KW, Kim AY, Kim PN, Ha HK, et al. Anatomic variation in intrahepatic bile ducts: An analysis of intraoperative cholangiograms in 300 consecutive donors for living donor liver transplantation. Korean J Radiol 2003;4:85 90.

[12]. Hirono Y, Takita Y, Nitta N, Hashimoto H. Double cystic duct found by intraoperative cholangiography in laparoscopic cholecystectomy. Surg Laparosc Endosc 1997;7:263-265.

[13]. Cachoeira E, Rivas A, Gabrielli C Anatomic Variations of Extrahepatic Bile Ducts and Evaluation of the Length of Ducts Composing the Cystohepatic Triangle. Int. J. Morphol., 2012;30(1):279-283.

[14]. Caroli-Bosc, F. X.; Demarquay, J. F.; Conio, M.; Deveau, C.; Hastier, P. \& Harris, A. Is biliary lithogenesis affected by length and implantation of cystic duct? Study of 270 patients with endoscopic retrograde cholangiopancreatography. Dig. Dis. Sci., 1997;(10):2045-51.

[15]. H. Onder, M. S. Ozdemir, G. Tekbas, F. Ekici, H. G"um"us, and A. Bilici. 3-T MRI of the biliary tract variations. Surgical and Radiologic Anatomy, 2013;35(2):161-167.

[16]. K. J. Mortel'e, T. C. Rocha, J. L. Streeter, and A. J. Taylor. Multimodality imaging of pancreatic and biliary congenital anomalies. Radiographics, 2006;26(3):715-731.

[17]. P. Taourel, P. M. Bret, C. Reinhold, A. N. Barkun, and M. Atri, "Anatomic variants of the biliary tree: diagnosis with MR cholangiopancreatography," Radiol ogy 1996;199(2):521- 527.

[18]. I. Tsitouridis, G. Lazaraki, C. Papastergiou, E. Pagalos, and G. Germanidis, "Low conjunction of the cystic duct with the common bile duct: does it correlate with the formation of common bile duct stones?" Surgical Endoscopy and Other Interventional Techniques, 2007;21(1):48-52.

[19]. Turner MA, Fulcher A. The Cystic Duct: Normal Anatomy and Disease Processes. RadioGraphics 2001; 21:3-22

[20]. Theodoros E. Pavlidis et al - Long, Parallel Cystic Duct in Laparoscopic Cholecystectomy for Acute Cholecystitis: the Role of Magnetic Resonance Cholangiopancreatography, JSLS 2008;12:407-409.

[21]. Arun Kumar S. Bilodi, Gangadhar MR - Cystic Duct Remnant Syndrome Associated with Symptomatic Dilatation of Cyst Duct, International Journal of Anatomical Sciences 2011;2(2):34-36

[22]. K. J. Mortel'e and P. R. Ros, "Anatomic variants of the biliary tree: MR cholangiographic findings and clinical applications," American Journal of Roentgenology, 2001;177(2):389-394.

[23]. Kwon AH, Uetsuji S, Ogura T, Kamiyama Y. Spiral computed tomography scanning after intravenous infusion cholangiography for biliary duct anomalies. Am J Surg 1997;174:396-401.

[24]. F. Selvaggi, G. Cappello, A. Astolfi et al., "Endoscopic therapy for type B surgical biliary injury in a patient with short cystic duct," || Giornale di Chirurgia 2010;31(5):229-232.

[25]. Hirao K, Miyazaki A, Fujimoto T, Isomoto I, Hayashi K. Evaluation of Aberrant Bile Ducts Before Laparoscopic Cholecystectomy AJR September 2000;175(3):713-720.

[26]. Adam Y, Metcalf W. Absence of the cystic duct: a case report, the embryology and a review of the literature. Ann Surg 1966;164:1056 -1058.

[27]. Allan S, Hurrell TA. Agenesis of the gallbladder and cystic duct: a report of 3 cases. $\mathrm{Br} J$ Surg 1974;61:145-146.

[28]. Bogardus GM, Lundmark VO. The short or absent cystic duct. Surgery 1969;65:274 -275.

[29]. Lewis FT. Development of the liver. In: Keibel, Mall, editors. Manual of embryology, Vol. II. Philadelphia: J.B. Lippincott, 1912;403.

[30]. L. G. Awazli. Anatomical variations of extrahepatic biliary system," Iraqi Journal of Medical Science, 2013;11(3):258-264.

[31]. Cachoeira E, Rivas A, Gabrielli C Anatomic Variations of Extrahepatic Bile Ducts and Evaluation of the Length of Ducts Composing the Cystohepatic Triangle. Int. J. Morphol., 2012;30(1):279-283.

[32]. Lamah M, Dickson GH. Congenital anatomical abnormalities of the extrahepatic biliary duct: a personal audit. Surgical and Radiologic Anatomy 1999;21(5):325-327.

[33].Dia A, Venditelli F, Valleix D, Descottes B. Le canal cystique double. A propos d'un cas. Ann Chir 1989;43:306 -308.

How to cite this article: Ali Yasen Yasen MohamedAhmed , Alaa A. Salih, Mohamed Alsadiq Abdallah Adam, Salma Saeed Sulaiman Mohammed, Mohamed Elghazali Ahmed Basheer Elhasan, Mohamed Ahmed Abdalla. ANATOMICAL VARIATIONS OF THE CYSTIC DUCT AND THEIR SURGICAL IMPLICATIONS IN SUDANESE POPULATION: A CADAVERIC STUDY. Int J Anat Res 2019;7(2.1):6416-6419. DOI: 10.16965/ijar.2019.131 